\title{
Sponged Structured Silica Containing Cobalt Oxide as Catalyst for Hydrolysis of Water Solution of Sodium Borohydride
}

\author{
Jon Efendi ${ }^{1,2 *}$, Lai Sin Yuan ${ }^{1}$, Hadi Nur ${ }^{1}$ \\ ${ }^{1}$ Ibnu Sina Institute for Fundamental Science, Universiti Teknologi Malaysia, 81310 UTM Skudai, Johor Darul Ta'zim \\ ${ }^{2}$ Department of Chemistry, Universitas Negeri Padang, Jl. Prof. Hamka, Air Tawar, Padang, West Sumatera, Indonesia \\ Received 1 June 2011, Revised 15 August 2011, Accepted 10 September 2011, Available online 5 December 2011
}

\begin{abstract}
Micro structured silica containing cobalt oxide materials was prepared by the calcination of silica containing cobalt salicylaldimine complexes. The SEM image showed that the prepared materials from higher content of cobalt salicylaldimine complexes had sponge-like structured. The IR and DR UVVis, spectra confirmed the presence of different species of cobalt oxide in materials originated from higher contain of the complex, which is attributed as $\mathrm{Co}_{3} \mathrm{O}_{4}$. The $\mathrm{Co}_{3} \mathrm{O}_{4}$ was believed as active species in catalytic hydrolysis of sodium borohydride. The catalytic testing also showed that the material originated from higher content of complex generated much higher hydrogen gas compare to the lower ones.
\end{abstract}

| Sponge structured | silica | cobalt oxide | catalyst |

( 2011 Ibnu Sina Institute. All rights reserved. http://dx.doi.org/10.11113/mjfas.v7n2.251

\section{INTRODUCTION}

Hydrogen storage is one of the most important problems in hydrogen economy. Various materials which have been intensively studied, for example, the complex hydrides such as $\mathrm{NaBH}_{4}, \mathrm{LiBH}_{4}, \mathrm{NaAlH}_{4}, \mathrm{Mg}\left(\mathrm{BH}_{4}\right)_{2}$, $\mathrm{NH}_{3} \mathrm{BH}_{3}$, which are among the attractive hydrogen storage materials [1]. Sodium borohydride $\left(\mathrm{NaBH}_{4}\right)$ has attracted attention since the late 1990's because of its high content of hydrogen of as high as 10.7 wt. \%, high stability of its alkali solutions, non-toxicity and fire-safety [2-4]. In addition, this hydride is the least expensive and commercially available. It is one of the best candidates to be used in portable devices [5].

$\mathrm{NaBH}_{4}$ both liberate hydrogen upon hydrolysis at ambient temperature only in the presence of suitable catalysts as shown in (1) and (2), respectively:

$\mathrm{NaBH}_{4}+2 \mathrm{H}_{2} \mathrm{O} \rightarrow \mathrm{NaBO}_{2}+4 \mathrm{H}_{2}$

$\mathrm{NH}_{3} \mathrm{BH}_{3}+2 \mathrm{H}_{2} \mathrm{O} \rightarrow \mathrm{NH}_{4} \mathrm{BO}_{2}+3 \mathrm{H}_{2}$

Most of the published papers about the hydrolysis of $\mathrm{NaBH}_{4}$ deal with improvement of catalytic materials. Different acids and metal-based systems have been studied as catalysts for these hydrolysis processes $[3,6]$. The catalysts containing noble metals $\mathrm{Pt}, \mathrm{Rh}, \mathrm{Ru}$ (supported or not) have shown the best performance [2,7]. However the high cost of these catalysts has initiated studies into the development of catalytic systems not requiring noble metals.

Corresponding author at : Ibnu Sina Institute for Fundamental Science, Universiti Teknologi Malaysia, 81310 UTM Skudai, Johor Darul Ta'zim Email: efendi@ibnusina.utm.my
The most promising among them are the cobalt-based catalysts such as Co nanoparticles [8], Au@Co core-shell nanoparicles [9], cobalt salts, cobalt oxides [10], Cu/Co3O4 [11], cobalt borides [12], Co-P [13], supported Cocontaining catalysts [14], etc

Recently, the high catalytic activity of $\mathrm{Co}_{3} \mathrm{O}_{4}$ and $\mathrm{LiCoO}_{2}$ in $\mathrm{NaBH}_{4}$ hydrolysis was reported [15]. It was suggested that in a $\mathrm{NaBH}_{4}$ water solution these oxides can be reduced to an active cobalt boride phase. Reduction of water-soluble cobalt salts in aqueous $\mathrm{NaBH}_{4}$ solutions is a well-known process [16]. The reduction occurred because cobalt exists in ionic species. However, the investigation of the reduction of impregnated cobalt oxides on the support, for example silica, under the action of hydride solutions has not been clear yet. This data is important for understanding the catalytic action mechanism of silica containing cobalt oxide catalysts during hydrolysis.

In this paper silica containing cobalt oxide catalysts were prepared by calcinations of their corresponding salicylaldimine complexes and their activity in hydrolysis $\mathrm{NaBH}_{4}$ had been investigated. The catalytic activity of the silica containing cobalt oxide has been compared with that of the material formed from calcinated cobalt carbonate.

\section{MATERIALS AND METHODS}

\subsection{Synthesis of cobalt salicyladimine complex}

Cobalt(II) salicylaldimine complex (0.01 mol) in 10 $\mathrm{ml}$ ethanol is added into silica nanoparticles. The mol ratio 
of complex and TEOS were varied from 1 to 1 until 1 to 4 . The mixture was reflux for 3 hours at $80{ }^{\circ} \mathrm{C}$. The mixture is stirred overnight. The resulting solid then washed with three portion of $5 \mathrm{ml}$ water followed by three portion of $5 \mathrm{ml}$ hexane. The solid was allowed to dry in open air.

\subsection{Synthesis silica porous silica containing containing cobalt oxide}

Silica containing cobalt oxide was prepared by calcinations of the silica containing cobalt complexes for 24 hours by $550{ }^{\circ} \mathrm{C}$. The calcined product had no further treatment and was kept in vacuum desiccators before used.

\subsection{Characterization}

The synthesized catalysts were characterized by Xray Diffraction (XRD), Diffuse Reflectance Ultraviolet Visible (DRUV-Vis), Scanning Electron Microscope (SEM), and Fourier Transform Infrared (FTIR) with $\mathrm{KBr}$ pellet method.

\subsection{Catalytic testing}

Hydrogen generation experiments were carried out at room temperature in a round bottom Flask quipped with a magnetic stirrer at an $800 \mathrm{rpm}$ stirring rate. A freshly prepared aqueous solution $\left(\mathrm{V}=10 \mathrm{ml}\right.$ ) of $\mathrm{NaBH}_{4}$ (Acros Organics, 98\%) or was placed into the reactor. The content of hydrides in $10 \mathrm{ml}$ of distilled water is shown in Table 1. The catalyst $(0.0117 \mathrm{~g})$ was added and the volume of generated hydrogen was measured with a gas burette.

\section{RESULTS \& DISCUSSION}

\subsection{Silica containing cobalt oxide performance in $\mathrm{NaBH}_{4} \mathrm{Hydrolysis}$}

The $\mathrm{H}_{2}$ generation vs. time during hydrolysis of sodium borohydride over Silica containing cobalt oxide is shown in Fig. 1. There was an increase of hydrogen generation toward the increase of silica/complex ratio. The catalyst with higher ratio of silica/complex generated hydrogen much higher than the lower ratio and the pure cobalt oxide. The increasing might be due to the number of active cobalt oxide in the silica matrix. It was believed that the amount of impregnated cobalt oxide in silica matrix increased with the increase number of the complex in silica. This result also showed that cobalt oxide was active site of the catalyst.

Comparing pure cobalt oxide and silica containing cobalt oxide in hydrogen generation indicated that the species function as an active site in catalyst molecule may be different. This difference in activity of hydrogen release supports by IR spectra (Fig. 2). The IR spectra showed the different species of cobalt in the silica matrix with the increasing of the ratio silica complex. The catalyst material with higher ratio complex to TEOS (1 to 3 and 1 to 4 ) shows medium band at $664 \mathrm{~cm}^{-1}$ and $580 \mathrm{~cm}^{-1}$. This band could be attributed to $\mathrm{Co}_{3} \mathrm{O}_{4}$ species. These bands did not exist for catalyst with lower ratio complex to TEOS.

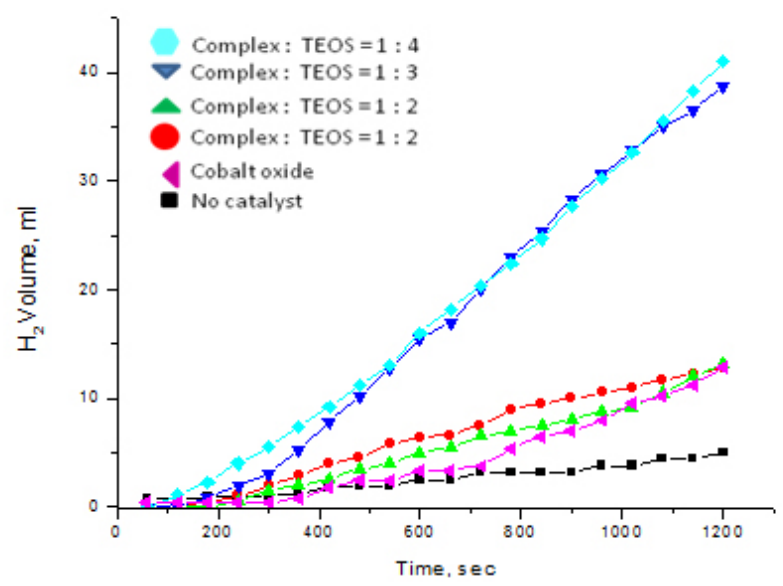

Fig. $1 \mathrm{H}_{2}$ generation from hydride solutions over cobalt containing catalyst $(0.0117 \mathrm{~g})$.

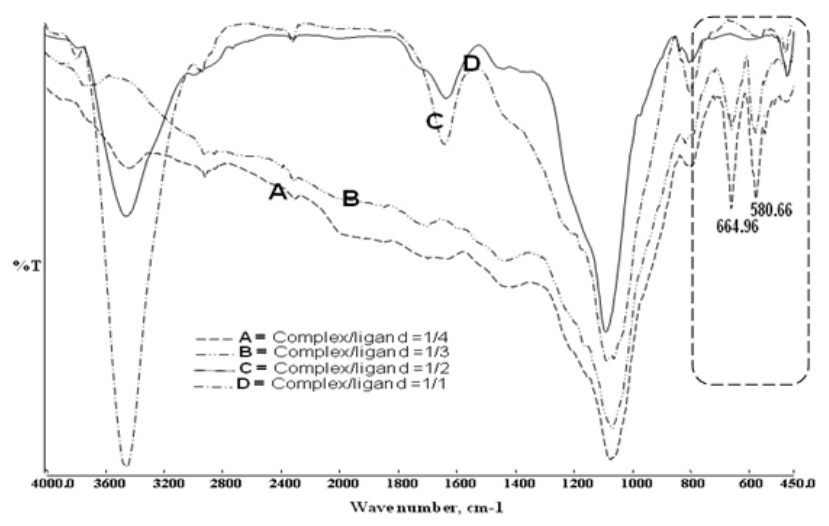

Fig. 2 FTIR spectra of silica containing cobalt oxide by variation of ratio complex/TEOS

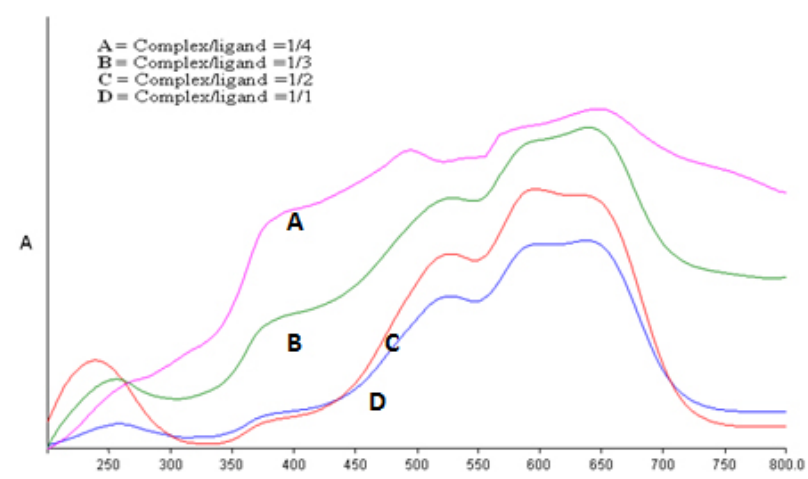

Fig. 3 DR UV-Vis spectra of silica containing cobalt oxide by variation of ratio complex/TEOS 

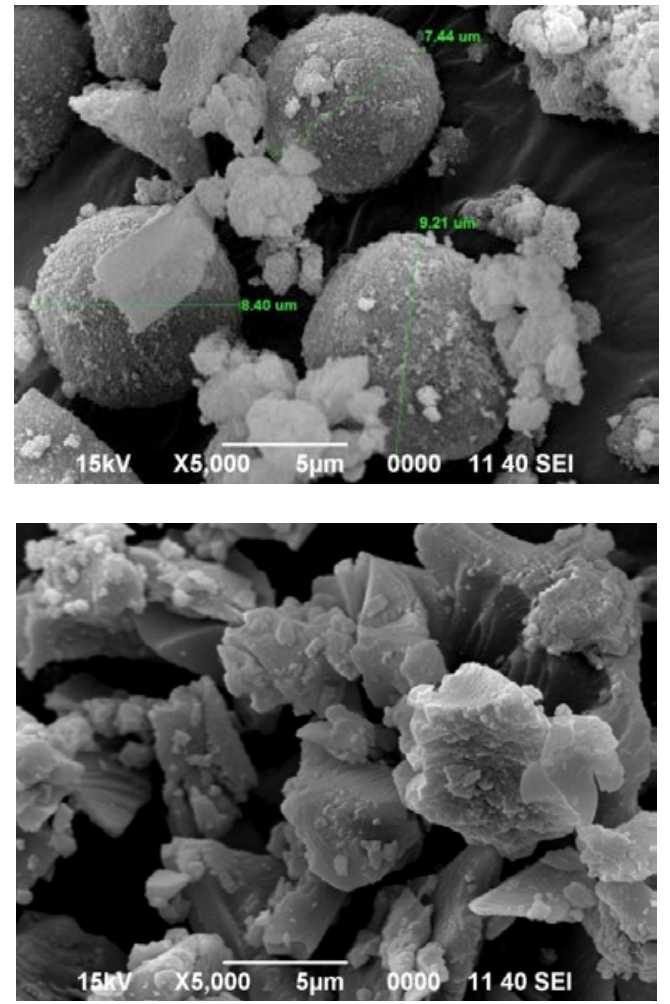

Fig. 4 SEM image of the silica containing cobalt oxide with the ratio complex/TEOS $1 / 1$ and $1 / 2$.
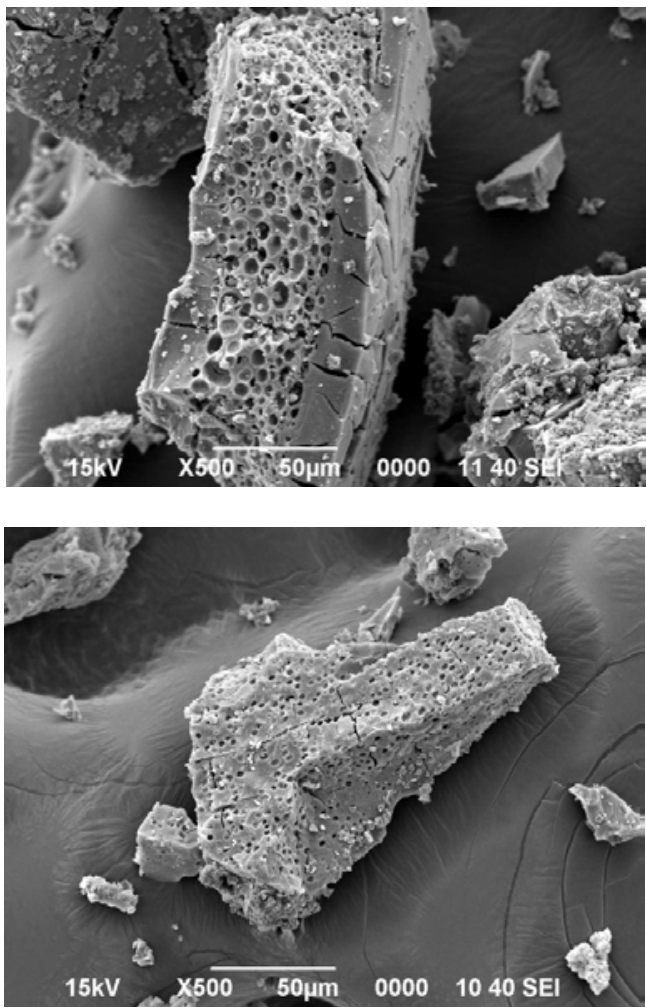

Fig. 5 SEM image of the silica containing cobalt oxide with the ratio complex/TEOS $1 / 3$ and $1 / 4$
The existance of $\mathrm{Co}_{3} \mathrm{O}_{4}$ species were also proved by DR UV-Vis spectra (Fig. 3). Both catalysts with from higher ratio of complex showed additional shoulders at higher wave length. These shoulders at $780 \mathrm{~nm}$ indicated that cobalt oxide in form of $\mathrm{Co}_{3} \mathrm{O}_{4}$ start to be present. The triplet at 520, 640 and $720 \mathrm{~nm}$ peaks could be ascribed to the presence of the $\mathrm{Co}^{2+}$ in tetrahedral sites, presumable $\mathrm{Co}(\mathrm{OH})_{4}$ or $\mathrm{CoO}_{4}$ predominately with minor octahedral ones [16]. The shoulder at $400 \mathrm{~nm}$ has been assigned to the coordination of Cobalt with Si-O-Si group.

The morphology of the catalyst material from SEM data showed the different structure with the increase of complex/TEOS ratio. The catalysts with complex/TEOS ratio 1:1 and 1:2 ratios showed no porous structured (Fig.4). But the catalysts with $1: 3$ and $1: 4$ ratios of silica : complex have porous and showed sponged structure material (Fig.5). The pore may be use to account for the high catalytic activity of the catalyst originated from silica with higher content of complex in hydrolysis of $\mathrm{NaBH}_{4}$. It was also believed that the active cobalt oxide, $\mathrm{Co}_{3} \mathrm{O}_{4}$, could be present as nanosize of cobalt oxide on the surface and inside the pore. Thus this pore offered more active site for the hydrolysis $\mathrm{NaBH}_{4}$ along with the presence of the nanosize active cobalt oxide site for higher ratio of complex toward TEOS.

\section{CONCLUSION}

The catalytic properties of silica containing cobalt oxide catalyst in catalytic hydrolysis of $\mathrm{NaBH}_{4}$ had been studied. According to the volume of hydrogen released, silica containing cobalt oxide originated from silica contain higher ratio of complex to silica showed higher catalytic activity. It is reasonable to assume that the higher the complex content in silica the higher the active cobalt oxide forms. The FTIR and DR UV-Vis spectra also confirmed the presence of active cobalt oxide species, $\mathrm{Co}_{3} \mathrm{O}_{4}$, in catalyst materials originated from silica with higher ratio of complex to silica. It might be function as an active site in catalytic hydrolysis of $\mathrm{NaBH}_{4}$. The corresponding silica containing active cobalt species show much higher catalytic activity compare to the others. SEM image also showed that catalysts originated from higher content of cobalt salicyladimine complex were porous material. This material showed a sponge structured material. It was believed that active cobalt oxide existed on the surface and in the pore of the catalyst, and it responsible for the higher catalytic activity.

\section{ACKNOWLEDGEMENTS}

The authors acknowledge the Ministry of Science, Technology and Innovation, Malaysia for financial support through Universiti Teknologi Malaysia through Research University Grant. 


\section{REFERENCES}

[1] S. Orimo, Y. Nakamori, J.R. Eliseo, A. Züttel, C.M. Jensen, Chem. Rev. 107 (2007) 4111-4132.

[2] S.C. Amendola, S.L. Sharp-Goldman, M.S. Janjua, N.C. Spencer, M.T. Kelly, P.J. Petillo, M. Binder, Int. J. Hydrogen Energy 25 (2000) $969-975$.

[3] H.I. Schlesinger, H.C. Brown, A.E. Finholt, J.R. Gilbreath, H.R. Hoekstra, E.K. Hyde, J. Am. Chem. Soc. 75 (1953) $215-219$.

[4] V.G. Minkina, S.I. Shabunya, V.I. Kalinin, V.V. Martynenko, A.L. Smirnova, Int. J. Hydrogen Energy 33 (2008) 5629-5635.

[5] U.B. Demirci, P. Miele, Energy Environ. Sci. 2 (2009) 627-637.

[6] P.A. Storozhenko, R.A. Svitsyn, V.A. Ketsko, A.K. Buryak, A.V. Ul’yanov, Russ. J. Inorg. Chem. 50 (2005) 980-985.

[7] F.H. Stephens, V. Pons, R.T. Baker, Dalton Trans. 25 (2007) 2613-2626. [8] Q. Xu, M. Chandra, J. Alloys Compd. 446-447 (2007) 729-732.

[9] T. Umegaki, J.-M. Yan, X.-B. Zhang, H. Shioyama, N. Kuriyama, Q. Xu, Int. J. Hydrogen Energy 34 (2009) $2303-2311$.

[10] H.-L. Jiang, S.K. Singh, J.-M. Yan, X.-B. Zhang, Q. Xu, ChemSusChem 3 (2010) 541.

[11] M. Chandra, Q. Xu, J. Power Sources 156 (2006) 855-860.

[12] Y. Kojima, K.I. Suzuki, K. Fukumoto, M. Sasaki, T. Yamamoto, Y. Hawai, H. Hayashi, Int. J. Hydrogen Energy 27 (2002) $1029-1034$.

[13] M. Chandra, Q. Xu, J. Power Sources 156 (2006) 190-194.

[14] V.I. Simagina, P.A. Storozhenko, O.V. Netskina, O.V. Komova, G.V. Odegova, Y.V. Larichev, A.V. Ishchenko, A.M. Ozerova, Catal. Today 133 (2008) 253-259.

[15] Ö. Metin, S. Özkar, Energy Fuels 23 (2009) 3517-3526.

[16] J. Andrieux, D. Swierczynski, L. Laversenne, A. Garron, S. Bennici, C. Goutaudier, P. Miele, A. Auroux, B. Bonnetot, Int. J. Hydrogen Energy 34 (2009) 938-951 